Article

\title{
Variation in a Newly Identified Caprine KRTAP Gene Is Associated with Raw Cashmere Fiber Weight in Longdong Cashmere Goats
}

\author{
Mengli Zhao ${ }^{1,2}$, Huitong Zhou ${ }^{2,3}$, Yuzhu Luo ${ }^{1,2} \mathbb{D}$, Jiqing Wang ${ }^{1,2}, \mathbb{D}^{D}$, Jiang Hu ${ }^{1,2}$, Xiu Liu ${ }^{1,2}$, Shaobin Li 1,2 ${ }^{1}$, \\ Kaiwen Zhang ${ }^{4}$, Huimin Zhen ${ }^{1,2}$ and Jon G. H. Hickford $2,3, * \mathbb{D}$
}

1 Gansu Key Laboratory of Herbivorous Animal Biotechnology, College of Animal Science and Technology, Gansu Agricultural University, Lanzhou 730070, China; zhaoml@st.gsau.edu.cn (M.Z.); luoyz@gsau.edu.cn (Y.L.); huj@gsau.edu.cn (J.H.); liux@gsau.edu.cn (X.L.); lisb@gsau.edu.cn (S.L.); zhenhm@st.gsau.edu.cn (H.Z.)

2 International Wool Research Institute, Gansu Agricultural University, Lanzhou 730070, China; huitong.zhou@lincoln.ac.nz

3 Gene-Marker Laboratory, Faculty of Agriculture and Life Sciences, Lincoln University, Lincoln 7647, New Zealand

4 Program in Developmental and Stem Cell Biology, Research Institute, The Hospital for Sick Children, University of Toronto, Toronto, ON M5G 0A4, Canada; kw.zhang@mail.utoronto.ca

* Correspondence: wangjq@gsau.edu.cn (J.W.); Jon.hickford@lincoln.ac.nz (J.G.H.H.); Tel.: +86-931-763-2469 (J.W.); +64-3423-0665 (J.G.H.H.)

check for updates

Citation: Zhao, M.; Zhou, H.; Luo, Y.; Wang, J.; Hu, J.; Liu, X.; Li, S.; Zhang, K.; Zhen, H.; Hickford, J.G.H.

Variation in a Newly Identified Caprine KRTAP Gene Is Associated with Raw Cashmere Fiber Weight in Longdong Cashmere Goats. Genes 2021, 12, 625. https://doi.org/ $10.3390 /$ genes 12050625

Academic Editor: Miloš Macholán

Received: 16 March 2021

Accepted: 15 April 2021

Published: 22 April 2021

Publisher's Note: MDPI stays neutral with regard to jurisdictional claims in published maps and institutional affiliations.

Copyright: (C) 2021 by the authors. Licensee MDPI, Basel, Switzerland. This article is an open access article distributed under the terms and conditions of the Creative Commons Attribution (CC BY) license (https:/ / creativecommons.org/licenses/by/ $4.0 /)$.

\begin{abstract}
Keratin-associated proteins (KAPs) and keratins determine the physical and chemical properties of cashmere fibers as they are the main components of the fibers. It has been reported that ovine KRTAP1-2 affects clean fleece weight, greasy fleece weight and yield in sheep, but the gene has not been described in goats and its effects on fiber traits are unknown. In this study, we identify the keratin-associated protein 1-2 gene (KRTAP1-2) in the goat genome and describe its effect on cashmere fiber traits in 359 Longdong cashmere goats. Six sequence variants (named CAPHIKRTAP1-2*A to CAPHI-KRTAP1-2* F) were revealed using polymerase chain reaction-single strand conformation polymorphism (PCR-SSCP) analysis. These sequences have the highest homology with ovine KRTAP1-2 sequences. There were a 60-bp deletion, a 15-bp insertion and five single nucleotide polymorphisms (SNPs) including two non-synonymous SNPs in the coding sequence. The caprine KRTAP1-2 gene was expressed in the skin tissue, but a signal was not observed for the kidneys, liver, lungs, spleen, heart and longissimus dorsi muscle. Variation in caprine KRTAP1-2 was found to be associated with raw cashmere fiber weight, but not with fiber diameter and length.
\end{abstract}

Keywords: KRTAP1-2; polymerase chain reaction-single strand conformation polymorphism; cashmere fiber traits; gene expression

\section{Introduction}

The Longdong cashmere goat is a special breed of goat farmed in the Longdong area of the Gansu Province. This breed has been created as a cross between the Ziwuling black goat, the Inner Mongolian cashmere goat and the Liaoning cashmere goat (Supplementary Materials Figure S1). While the Longdong cashmere goat is well-adapted to harsh environments including desert and other arid regions, it has lower cashmere fiber yields (average of $400 \mathrm{~g}$ per annum) than the Liaoning cashmere goat (average of $640 \mathrm{~g}$ ) and the Inner Mongolian cashmere goat (average of $450 \mathrm{~g}$ ). The identification and understanding of genes that regulate cashmere fiber growth and structure is therefore important for improving the yield of cashmere fiber in Longdong cashmere goats.

Cashmere fibers are produced by secondary hair follicles and the fibers are characterized as being soft, elastic and strong, and they provide good thermal insulation. As with 
wool and hair, the most common protein structural components of cashmere fibers are keratins and keratin association proteins (KAPs), with the latter serving as a matrix that cross-links with the keratins via disulfide bond formation [1].

The KAPs have historically been classified into three categories depending on their content of the amino acids-cysteine, or glycine/tyrosine [2]. They are typically encoded by small intron-less genes called KRTAPs, and over 100 KRTAPs from 29 families have been identified across mammalian species [2-4]. Over the last four decades, the identification of KRTAPs and research into the effect of these genes on hair and wool traits has been most commonly focused on humans and sheep. However, to date, only 17 KRTAPs have been identified from 13 families in goats [5-9].

The genetic similarity between sheep and goats suggests that many KRTAPs remain to be identified in the goat genome. Of the 17 caprine KRTAPs identified to date, seven of them have been reported to affect cashmere fiber length, cashmere fiber yield and cashmere mean fiber diameter, including KRTAP8-2 [10], KRTAP20-2 [11], KRTAP20-1 [12], KRTAP15-1 [6], KRTAP27-1 [9], KRTAP28-1 [8] and KRTAP24-1 [7]. This suggests that nucleotide sequence variation in the caprine KRTAPs is an important determinant of key cashmere traits.

The KAP1 proteins are encoded by a gene family that is well characterized in sheep, with four variable ovine KRTAP1s identified: KRTAP1-1, KRTAP1-2, KRTAP1-3 and KRTAP14 [13-15]. The ovine KRTAP1s are located on ovine chromosome 11, and in proximity to where quantitative trait locus (QTLs) for wool weight and staple strength have been found [16]. The 'QTSCCQPXXX' decapeptide repeat in the N-terminal region is a common characteristic of the ovine KAP1 family $[2,15,17]$, and the family displays a strong coevolutionary pattern within and between species [18].

Of the KAP1 genes, ovine KRTAP1-2 is expressed in the cortex of the wool fiber $[15,19]$. Eleven variants and 10 single nucleotide polymorphisms (SNPs) have been detected for ovine KRTAP1-2, and the presence of some of these has been associated with wool yield, greasy fleece weight and clean fleece weight [19]. Taken together, the evidence suggests that ovine KRTAP1-2 variation may allow improvement in wool production, and hence it might be speculated that caprine KRTAP1-2 may be important for fiber production in goats too.

The aim of this study was to identify caprine KRTAP1-2 and to assess the relationship between variation in the gene and fiber traits in Longdong cashmere goats. The expression of KRTAP1-2 in different caprine tissues was also investigated. This study may provide new insight into improving fiber traits for Longdong cashmere goats.

\section{Materials and Methods}

\subsection{Cashmere Fiber, Blood and Tissue Collection}

Three hundred and fifty-nine one-year-old Longdong cashmere goats from 11 unrelated sires were selected, with these being reared at the Yusheng Cashmere Goat Breeding Company in Huan County of the Gansu Province. The raw cashmere fiber weight was measured after it had been collected by combing. Small samples of the fibers were also collected from the mid-side region of each goat's body, and the cashmere fiber length and mean fiber diameter (MFD) were tested using the Optical Fiber Length and Diameter Analyzer OFDA4000 (EPCO, Shanghai, China) platform.

Additionally, three separate female twelve-month-old Longdong cashmere goats were slaughtered to collect tissue from the skin, kidneys, liver, lungs, spleen, heart, and longissimus dorsi muscle. The tissue samples were frozen and stored in liquid nitrogen prior to reverse-transcription PCR (RT-PCR) analysis.

Blood samples from these goats were collected onto FTA cards (Whatman BioScience, Middlesex, UK) and genomic DNA samples were prepared for subsequent analyses using a two-step washing procedure [20]. 


\subsection{Screening for Sequence Polymorphism in Caprine KRTAP1-2}

A Basic Local Alignment Search Tool (BLASTN) search (https:/ /blast.ncbi.nlm.nih. gov / Blast.cgi?PAGE_TYPE=BlastSearch; accessed on 15 November 2020) was undertaken of Caprine Genome Assembly ASM170441v1 using the ovine KRTAP1-2 coding sequence (GenBank sequence HQ897973). The sequence with the highest homology to ovine KRTAP12 sequence was hypothesized to be the putative caprine KRTAP1-2 sequence.

Polymerase Chain Reaction (PCR) primers (5'-TAACAACCCTCCTCTCAATCT-3' and 5'-TTCATGGACTGAAGTTGAACT-3') were designed to amplify the putative caprine KRTAP1-2 from this sequence. Amplifications were undertaken in $20-\mu \mathrm{L}$ reactions, which included the purified genomic DNA on a 1.2-mm punch of the FTA paper, $\mathrm{Mg}^{2+}(2.5 \mathrm{mM})$, Taq DNA polymerase (0.5U, Takara, Dalian, China), deoxyribonucleoside triphosphates (dNTPs) $(150 \mu \mathrm{M}$, Takara, Dalian, China), the primers $(0.25 \mu \mathrm{M}), 10 \times$ PCR buffer supplied with DNA polymerase enzyme $(2.0 \mu \mathrm{L})$ and deionized water $\left(\mathrm{dH}_{2} \mathrm{O}\right)$ to volume. The amplifications were carried out in Bio-Rad S1000 thermal cyclers (Bio-Rad, Hercules, CA, USA) and consisted of $5 \mathrm{~min}$ at $94^{\circ} \mathrm{C}$ for an initial denaturation, followed by 35 cycles of $30 \mathrm{~s}$ at $94{ }^{\circ} \mathrm{C}, 30 \mathrm{~s}$ at $53{ }^{\circ} \mathrm{C}, 30 \mathrm{~s}$ at $72{ }^{\circ} \mathrm{C}$, and lastly $5 \mathrm{~min}$ at $72{ }^{\circ} \mathrm{C}$ for a final extension. There was a test for PCR product amplification in $1 \times \mathrm{TBE}$ buffer using $1.0 \%$ agarose gels electrophoresis.

The PCR amplicons were subjected to single strand conformation polymorphism (SSCP) analysis. One microliter aliquots of the PCR amplification products were added to $8.0 \mu \mathrm{L}$ aliquots of loading dye (98\% formamide, $0.025 \%$ bromophenol blue, $0.025 \%$ xylene cyanol and $10 \mathrm{mM}$ ethylenediaminetetraacetic acid (EDTA) and then denatured for $10 \mathrm{~min}$ at $95{ }^{\circ} \mathrm{C}$. The mixtures were cooled on wet ice and then loaded on $16 \mathrm{~cm} \times 18 \mathrm{~cm}, 12 \%$ acrylamide: bisacrylamide (37.5:1) (Bio-Rad, Hercules, CA, USA) gel. Electrophoresis was carried out at $180 \mathrm{~V}$ for $23 \mathrm{~h}$ at $31.5^{\circ} \mathrm{C}$ in $0.5 \times$ TBE buffer using Protean II xi cells (Bio-Rad). After electrophoresis, the gels were stained to identify the DNA banding patterns using a method described by Byun et al. [21].

Amplicons that produced different SSCP patterns were then selected for DNA sequencing. Those amplicons that appeared to be homozygous according to SSCP analysis were directly sequenced in both directions at the Beijing Genomics Institute (Beijing, China), and those variants that were found only in a heterozygote form were prepared by the method of Gong et al. [22] and then sequenced in both directions at the Beijing Genomics Institute.

The DNAMAN (Lynnon BioSoft, Vaudreuil, QC, Canada) software (version 5.2.10) and ClustalW algorithm was used to align, translate and compare DNA sequences. A phylogenetic tree was built based on the predicted amino acid sequence using MEGA version 7.0 and a maximum-likelihood method.

\subsection{Reverse Transcription-Polymerase Chain Reaction (RT-PCR)}

Total RNA from the seven tissues isolated from the Longdong cashmere goats was extracted with Trizol (Invitrogen, Carlsbad, CA, USA). Spectrophotometry (ultraviolet range) and $2 \%$ agarose gels electrophoresis were then used to detect the concentration and determine quality of RNA, respectively.

The PrimeScript RT Reagent Kit with gDNA Eraser (Perfect Real Time, Takara, Dalian, China) was utilized for reverse transcription (RT) of the isolated total RNA to produce cDNA. Next, a PCR amplification with the cDNA as a template and the primers (5'-GTAGCAGCGGAGCTGTGAG-3' and 5'-CAGGACTGTCCACAGTAGGATG$\left.3^{\prime}\right)$ was used to produce a 170-bp fragment from within the coding sequences of caprine KRTAP1-2. The caprine $\beta$ actin gene (ACTB) was used as an internal reference standard in these analyses, with the primers of 5'-AGCCTTCCTTCCTGGGCATGGA-3' and 5'GGACAGCACCGTGTTGGCGTAGA-3' being used to amplify a fragment of this gene. The amplification conditions used were the same as for the genomic amplifications of KRTAP1-2 described above, but the genomic DNA was substituted with cDNA. The RT-PCR products from three female goats were then analyzed by agarose gels electrophoresis ( $1 \% w / v$ gels) to 
ascertain the presence and quality of the RT-PCR products in order to detect the expression of the gene in different tissues.

\subsection{Statistical Analyses}

General linear mixed-effect models (GLMMs) were used to assess the effect of variation in caprine KRTAP1-2 on cashmere fiber traits using IBM SPSS Statistics version 24.0 (IBM, Armonk, NY, USA). Single-variant models were firstly used to assess the effect of the absence or presence of individual caprine KRTAP1-2 variants on variation in the fiber traits. Based on these models, multi-variant models were then employed, with these analyzing the effect of the absence or presence of individual caprine KRTAP1-2 variants (but with them being corrected for other variants that had $P<0.10$ and that were therefore potentially affecting the trait). To confirm the variant absence or presence results from the multi-variant models, genotype comparisons were also carried out, with a Bonferroni correction being applied to reduce the probability of false positive results during the multiple comparisons in these models. Gender and sire were included in the GLMMs as a fixed and random factor, respectively, as they affected all the fiber traits $(P<0.05)$. Birth rank was excluded from the models as it did not affect the cashmere traits. Only the main effects were detected.

\section{Results}

\subsection{Identification of Caprine KRTAP1-2}

A BLASTN search using the ovine KRTAP1-2 coding sequence (HQ897973) revealed a highly similar sequence on the goat genome assembly sequence for chromosome 19 (NC_030826.1: nt 40916023 to 40916556). Subsequently, SSCP analysis of PCR amplicons amplified from this gene region revealed six different banding patterns ( $A$ to $F$ ) (Figure 1), and upon DNA sequencing, these were found to correspond to six unique DNA sequences, ranging in size from 557-bp to 617-bp (Figure 2).

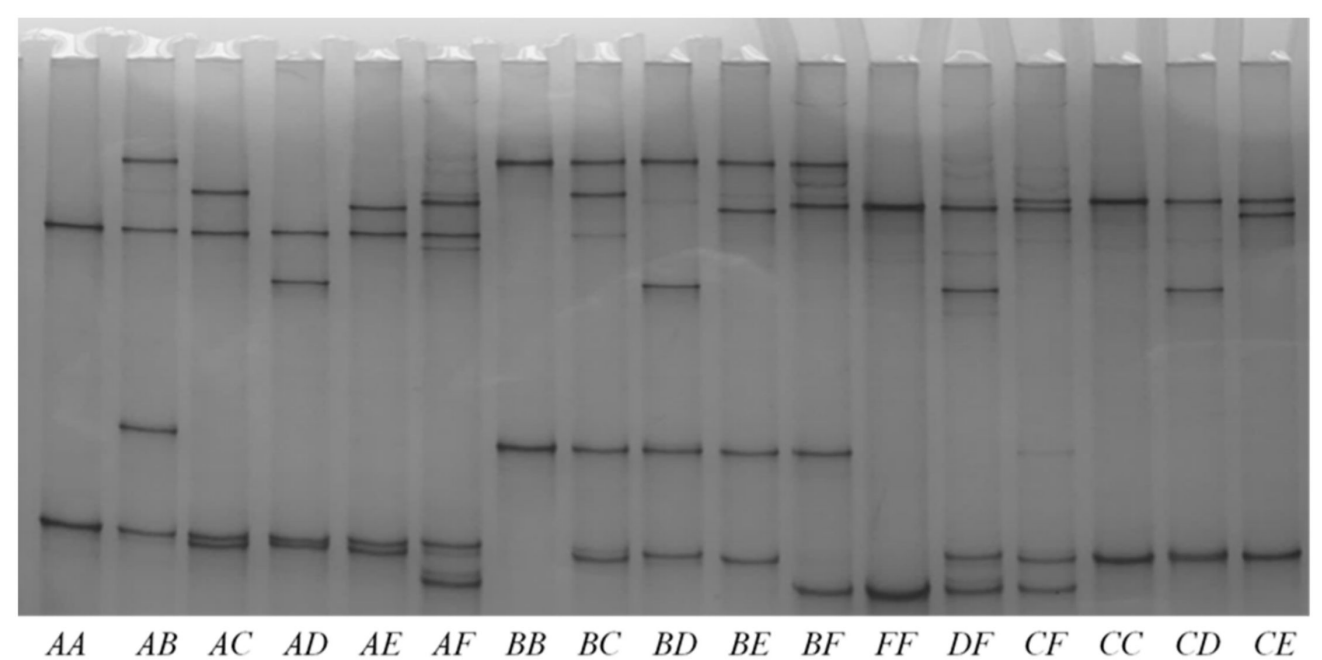

Figure 1. Polymorphism of caprine KRTAP1-2 identified using PCR-SSCP analysis. Six variants $(A-F)$ represented by six unique banding patterns were found in arrangements that appeared to correspond to either heterozygous or homozygous genotypes. 


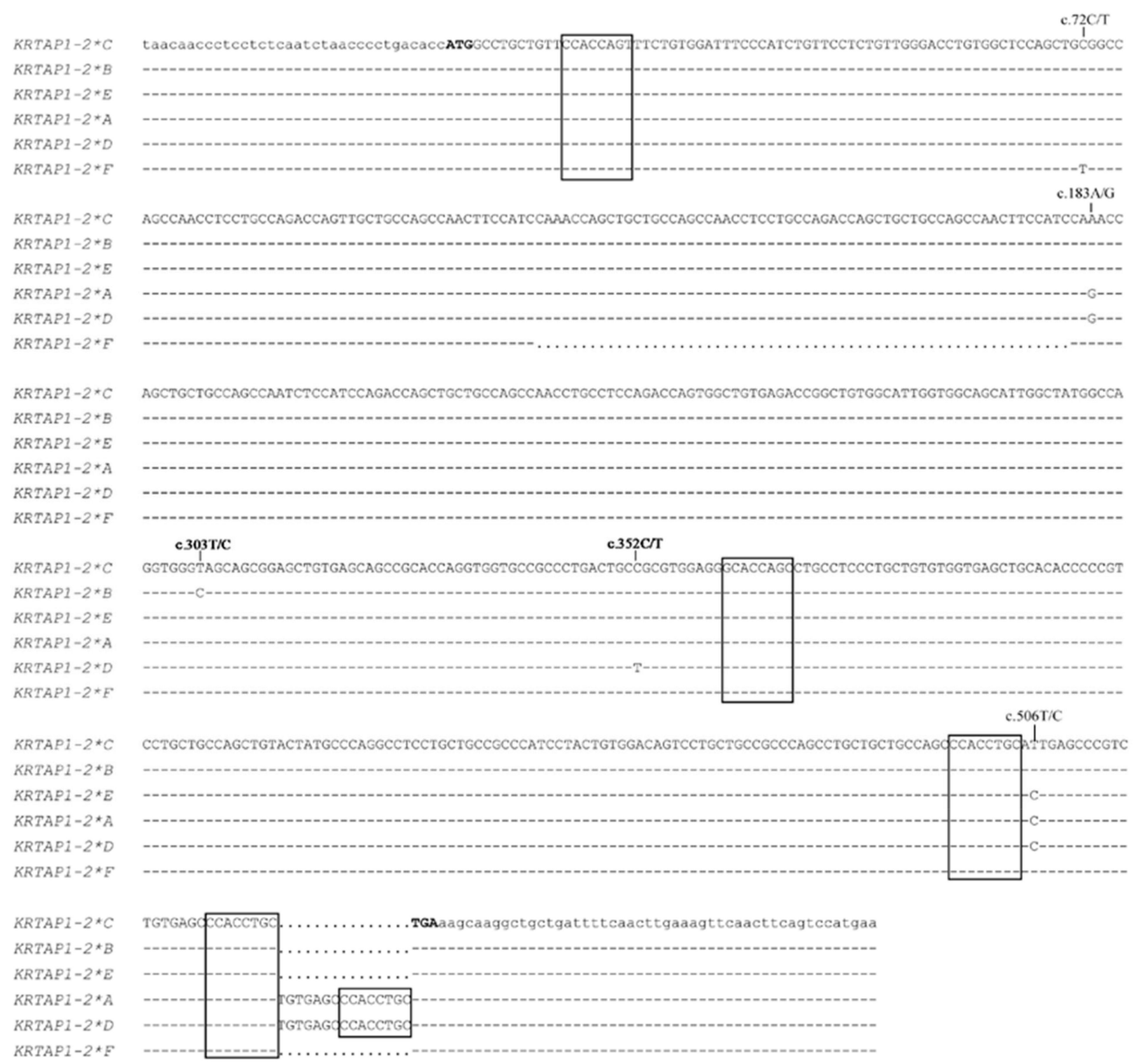

Figure 2. Nucleotide sequence alignment of the caprine KRTAP1-2 sequences. The dashes indicate the same nucleotide with respect to the sequence of caprine $K R T A P 1-2{ }^{*} \mathrm{C}$ and the dots represent nucleotide deletions. The single nucleotide polymorphisms identified among these sequences are indicated above the sequences. The notional ATG (start codon) and TGA (stop codon) are shown in bold, and the Chi-like sequences are shown in box. The uppercase letters indicate nucleotides in the coding region, whereas the lowercase letters indicate nucleotides in the non-coding region. The numbering of nucleotides and amino acid positions follows the Human Genome Variation Society (HGVS) nomenclature (http://varnomen.hgvs.org/; accessed on 15 November 2020).

In the 359 cashmere goats investigated, the frequencies of variants $A, B, C, D, E$ and $F$ were $28.13 \%, 24.65 \%, 38.86 \%, 1.53 \%, 2.51 \%$ and $4.32 \%$, respectively. The frequencies of six common genotypes were $8.91 \%, 13.93 \%, 20.61 \%, 7.24 \%, 16.71 \%$ and $16.43 \%$ for $A A, A B, A C$, $B B, B C$ and $C C$. Phylogenetic analysis suggested that the amino acid sequence predicted from the goat genome sequence identified was closer to sheep KAP1-2 than all of other HS-KAPs (Figure 3), suggesting that this was the caprine KAP1-2 gene, and also suggesting that the six sequences found are variants of caprine KRTAP1-2. 


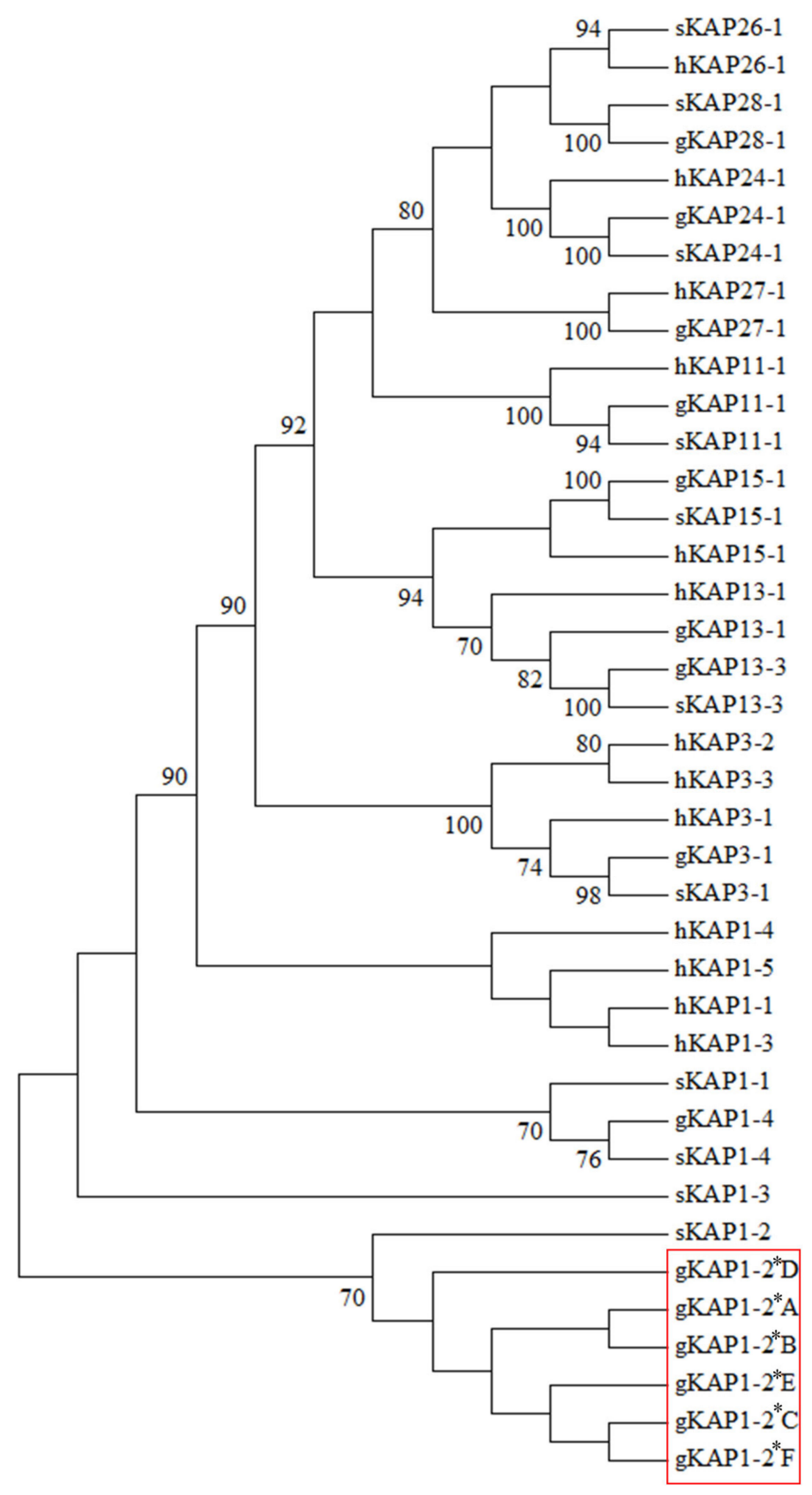

Figure 3. Phylogenetic tree of HS-KAPs identified in goats, humans and sheep. The putative amino acid sequences were used to construct the tree. The prefix " $\mathrm{g}$ " indicates the sequences from goats, while prefix " $s$ " and " $h$ " represent sequences from sheep and humans, respectively. The newly identified caprine KAP1-2 sequences are marked in a red box. The numbers at the forks represented the bootstrap confidence values with only those $\geq 70 \%$ being shown. The amino acid sequence of caprine KAP28-1 was adopted from Wang et al. [8]. The GenBank accession numbers for the other KAP sequences are: gKAP27-1 (MN934937), gKAP24-1 (MG996011), gKAP151 (NM_001285771), gKAP13-3 (JX426138), gKAP13-1 (AY510115), gKAP11-1 (NM_001285767.1), gKAP3-1 (NM_001285774), gKAP1-4 (JN012101.1), sKAP28-1 (MN053920), sKAP26-1 (KX644903), sKAP24-1 (JX112014), sKAP15-1 (MH742372), sKAP13-3 (JN377429), sKAP11-1 (HQ595352), sKAP31 (M21099), sKAP1-4 (GQ507741.1), sKAP1-3 (NM_001159761), sKAP1-2 (HQ897975), sKAP11 (X01610), hKAP27-1 (AB096937.1), hKAP26-1 (NM_203405.1), hKAP24-1 (NM_001085455.2), hKAP15-1 (NM_181623.2), hKAP13-1 (NM_181599.2), hKAP11-1 (NM_175858.2), hKAP3-3 (NM_033185.2), hKAP3-2 (NM_031959.2), hKAP3-1 (NM_031958.1), hKAP1-5 (NM_031957.1), hKAP14 (NM_001257305.1), hKAP1-3 (NM_030966.1) and hKAP1-1 (NM_030967.2). 
Based on the nomenclature suggested by Gong et al. [23], the KRTAP1-2 variants were named CAPHI-KRTAP1- $2 * A$ to CAPHI-KRTAP1- $2 * F$. Of these, CAPHI-KRTAP1- $2{ }^{*} C$ was identical to the Caprine Genome Assembly sequence (NC_030826.1: nt 40916023 to 40916556). Five Chi-like sequences were found in the caprine KRTAP1-2 sequences (Figure 2) and five SNPs were identified across the caprine KRTAP1-2 sequences. All of the SNPs were located within the coding region and these were c.72C/T, c.183A/G, c.303T/C, c.352C/T and c.506T/C (Figure 2). Two SNPs (c.352C/T and c.506T/C) were non-synonymous and would result in the putative amino acid changes of $\mathrm{p}$.Arg118Cys and p.Ile169Thr, respectively (Figure 4).

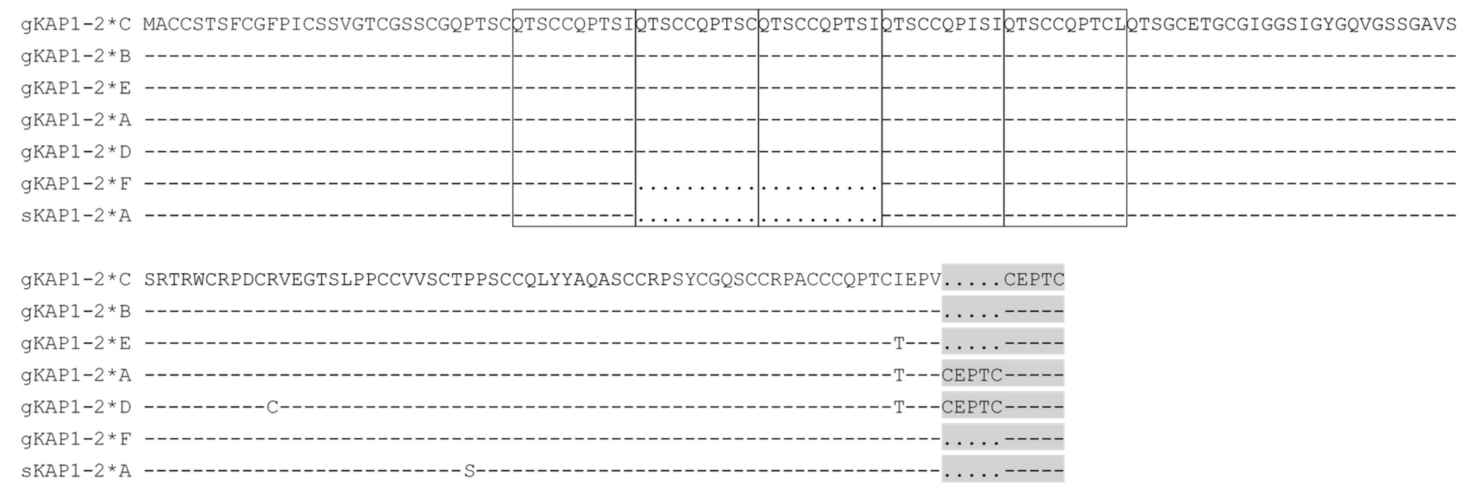

Figure 4. Alignment of the predicted amino acid sequences derived from the caprine KAP1-2 gene sequences and ovine KAP1-2 variant $A$. The prefix "g" and "s" stand for goat and sheep sequences, respectively. The dashes indicate identity with caprine KAP1-2*C and the dots represent amino acid deletions. The decapeptide 'QTSCCQPT(S/C)X' repeats are boxed, and pentapeptide 'CEPTC' repeats are shaded. The levels of cysteine (21.7-23.1\%) and serine (15.3-15.8\%) were high, while the content of threonine (9.6-11.5\%), proline (9.6-9.9\%), glutamine (8.3-9.6\%) and glycine (8.2-9.6\%) was moderate in the predicted polypeptide sequences encoded by caprine KRTAP1-2.

Aside from the SNPs, a 60-bp deletion and a 15-bp insert were also found for caprine KRTAP1-2 (Figure 2). The 60-bp deletion was located in a decapeptide repeat coding region and would result in three or five decapeptide repeats, i.e., multiples of QTSCCQPT(S/C)X in the middle region of the protein (Figure 4). The 15-bp insert was located in the repeat region upstream of the stop codon and would lead to one repeat of the pentapeptide (CEPTC) in some sequences and two repeats in the other sequences (Figure 4).

\subsection{Expression of Caprine KRTAP1-2 in Different Tissues}

The RT-PCR analysis revealed that caprine KRTAP1-2 only appeared to be expressed in the skin, but not in the kidneys, liver, lungs, spleen, heart, and longissimus dorsi muscle in all of the three Longdong cashmere goats tested, with the results from one of these goats being shown in Figure 5.

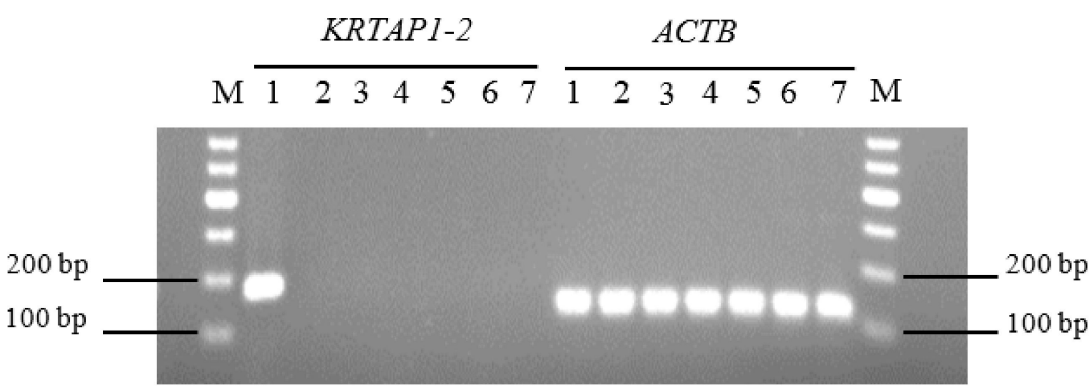

Figure 5. RT-PCR results for caprine KRTAP1-2 and $\beta$ actin (ACTB) mRNA presence in seven tissues of Longdong cashmere goats. The results obtained from three different goats were identical, so only the results from one of the goats is shown. M: DNA marker; 1: skin; 2: kidney; 3: liver; 4: lung; 5: spleen; 6: heart; and 7: longissimus dorsi muscle. 


\subsection{Effect of Variation in Cashmere KRTAP1-2 on Three Cashmere Fiber Traits}

Of the six KRTAP1-2 gene sequences identified in Longdong cashmere goats, only three (CAPHI-KRTAP1-2*A, CAPHI-KRTAP1-2*B and CAPHI-KRTAP1-2*C) occurred at a frequency of over $5 \%$, and hence, associations were only analyzed for these. The presence of CAPHI-KRTAP1-2* $B$ was found to be associated with a decreased cashmere fiber yield in the single-variant model and the association persisted in the multi-variant model when correcting for the effect of the other variants (Table 1). No associations were detected between variation in KRTAP1-2 and cashmere fiber diameter and length (Table 1). Goats with genotype $B B$ produced less cashmere fibers than goats with other common genotypes (Table 2).

Table 1. Associations between caprine KRTAP1-2 sequences and cashmere fiber traits (Mean $\pm \mathrm{SE})^{1}$.

\begin{tabular}{|c|c|c|c|c|c|c|c|}
\hline \multirow{2}{*}{ Cashmere Trait } & \multirow{2}{*}{ Variant Assessed } & \multirow{2}{*}{ Other Variants Fitted } & \multicolumn{2}{|c|}{ Absent } & \multicolumn{2}{|c|}{ Present } & \multirow{2}{*}{$P$ Value } \\
\hline & & & Mean \pm SE & $n$ & Mean $\pm S E$ & $n$ & \\
\hline \multirow{6}{*}{$\begin{array}{c}\text { Raw cashmere fiber } \\
\text { weight }(\mathrm{g})\end{array}$} & $A$ & None & $407.1 \pm 4.12$ & 145 & $416.0 \pm 4.05$ & 156 & 0.075 \\
\hline & $B$ & None & $419.5 \pm 3.73$ & 165 & $400.0 \pm 4.29$ & 136 & $<0.001$ \\
\hline & $C$ & None & $405.0 \pm 4.80$ & 108 & $414.6 \pm 3.61$ & 193 & 0.063 \\
\hline & $A$ & $B, C$ & $405.6 \pm 4.71$ & 145 & $412.2 \pm 4.17$ & 156 & 0.264 \\
\hline & $B$ & $A, C$ & $416.7 \pm 4.52$ & 165 & $401.1 \pm 4.41$ & 136 & 0.009 \\
\hline & C & $A, B$ & $405.9 \pm 5.19$ & 108 & $411.9 \pm 3.91$ & 193 & 0.345 \\
\hline \multirow{3}{*}{$\begin{array}{c}\text { Mean fiber } \\
\text { diameter }(\mu \mathrm{m})\end{array}$} & $A$ & None & $13.5 \pm 0.04$ & 145 & $13.6 \pm 0.04$ & 156 & 0.442 \\
\hline & $B$ & None & $13.7 \pm 0.04$ & 165 & $13.6 \pm 0.04$ & 136 & 0.977 \\
\hline & C & None & $13.6 \pm 0.04$ & 108 & $13.6 \pm 0.033$ & 193 & 0.357 \\
\hline \multirow{3}{*}{$\begin{array}{l}\text { Cashmere fiber } \\
\text { length }(\mathrm{cm})\end{array}$} & $A$ & None & $4.1 \pm 0.04$ & 145 & $4.2 \pm 0.04$ & 156 & 0.099 \\
\hline & $B$ & None & $4.2 \pm 0.04$ & 165 & $4.2 \pm 0.05$ & 136 & 0.373 \\
\hline & $C$ & None & $4.2 \pm 0.05$ & 108 & $4.2 \pm 0.04$ & 193 & 0.395 \\
\hline
\end{tabular}

\footnotetext{
${ }^{1}$ Estimated standard errors (SEs) and marginal means in general linear mixed effect model, with $P<0.05$ being shown in bold.
}

Table 2. Association between caprine KRTAP1-2 genotypes and cashmere fiber traits.

\begin{tabular}{cccc}
\hline \multirow{2}{*}{ Genotype } & \multicolumn{3}{c}{${\text { Mean } \pm \mathbf{S E}^{\mathbf{1}}}$} \\
\cline { 2 - 4 } & Raw Cashmere Fiber Weight (g) & Cashmere Fiber Length (cm) & Mean Fiber Diameter ( $\boldsymbol{\mu m})$ \\
\hline$A A(n=32)$ & $422.8 \pm 7.53^{\mathrm{a}}$ & $4.3 \pm 0.08$ & $13.6 \pm 0.07$ \\
$A B(n=50)$ & $408.6 \pm 6.16^{\mathrm{a}}$ & $4.2 \pm 0.07$ & $13.6 \pm 0.06$ \\
$A C(n=74)$ & $413.9 \pm 5.09^{\mathrm{a}}$ & $4.2 \pm 0.06$ & $13.6 \pm 0.05$ \\
$B B(n=26)$ & $369.6 \pm 8.49^{\mathrm{b}}$ & $4.1 \pm 0.10$ & $13.7 \pm 0.08$ \\
$B C(n=60)$ & $403.4 \pm 5.66^{\mathrm{a}}$ & $4.1 \pm 0.06$ & $13.5 \pm 0.05$ \\
$C C(n=59)$ & $423.1 \pm 5.55^{\mathrm{a}}$ & $4.2 \pm 0.06$ & $13.5 \pm 0.05$ \\
\hline$P$ value & $<0.001$ & 0.165 & 0.326 \\
\hline
\end{tabular}

\footnotetext{
${ }^{1}$ Estimated standard errors (SEs) and marginal means in general linear mixed effect model. Means that do not share a superscript letter
} (a or b) are significantly different at $P<0.01$.

\section{Discussion}

This study has identified a new caprine KRTAP and describes variation in this gene including the presence of SNPs, insertions and deletions. Some of the sequence variation detected was found to affect the cashmere fiber yield in Longdong cashmere goats. The gene appeared to only be expressed in goat skin tissue, albeit only six other tissues were tested and with a qualitative reverse transcription-polymerase chain reaction approach. We believe other tissues should be tested in future, especially follicle tissue, and with a quantitative RNA assay.

The newly identified caprine KRTAP sequences were phylogenetically closest to ovine KRTAP1-2 and was located in the same chromosomal region as caprine KRTAP13 and KRTAP1-4, suggesting that these new KRTAP sequences represent variants of caprine KRTAP1-2. 
The presence of multiple sequences of caprine KRTAP1-2 is consistent with the previous findings that all of the known KRTAPs are polymorphic [2,24]. The inserts/deletions detected for caprine KRTAP1-2 were associated with repeat regions and lead to variation in the number of repeats. This phenomenon has been described for some other KRTAPs, including KRTAP1-1, KRTAP5-4 and KRTAP6-5 in sheep [17,25,26] and KRTAP9-2 in goats [27], but it has not been detected for the KRTAP1-2 orthologue in sheep [2,24]. The presence of three or five QTSCCQPT(S/C)X repeats in the middle region of the putative protein, and one or two CEPTC repeats at the carboxyl-terminus, are similar to the three QTSCCQPT(S/C)X repeats and one CEPTC repeat in ovine KAP1-2, although they may have different functional effects in goats when compared to sheep. Providing evidence of this would, however, require considerably more investigation.

Caution is also needed in comparing the number and type of SNPs identified in these Longdong cashmere goats with sheep. While the number of SNPs found here appears to be less than has been described in the sheep orthologue, the goat SNPs were found in only 359 goats from one breed and one farm, whereas the sheep SNPs reported were discovered in larger numbers of sheep from variety of breeds and from different farms $[15,19]$. It is therefore reasonable to expect that more SNPs may be identified if more goats from more breeds and more farms are investigated. The SNPs identified in the two species are also located at different positions. This, together with length variation being present in caprine KRTAP1-2 but absent in ovine KRTAP1-2, suggests that different selection pressures may have acted upon sheep and cashmere goats.

There is literature reporting Chi or Chi-like sequences in KRTAPs from sheep and goats, including as ovine KRTAP1-n [17], ovine KRTAP15-1 [28], caprine KRTAP15-1 [6], caprine KRTAP24-1 [7] and caprine KRTAP27-1 [9]. Chi (crossover hotspot instigator, $\chi$ ) is an octamer motif (5'-GCTGGTGG-3') that has been described as a recombination hotspot in E. coli and related to the recombination of double-strand DNA breaks sites [29]. These Chi-like sequences detected in caprine KRTAP1-2 may therefore have contributed, at least in part, to the origin of sequence diversity in the gene.

There is only one SNP difference between CAPHI-KRTAP1-2*B and CAPHI-KRTAP1$2{ }^{*} C$ and that SNP was synonymous. The association with cashmere yield was detected for CAPHI-KRTAP1-2* $B$, but not for CAPHI-KRTAP1-2*C, suggesting that this synonymous SNP may either directly have a functional effect, or be linked to another region of the gene that has a functional effect. While synonymous SNPs do not lead to amino acid changes, they have been reported to at times regulate gene function by affecting mRNA secondary structure [30], mRNA stability [31] and the miRNA-based regulation of expression [32]. It is also possible that the effect detected for CAPHI-KRTAP1-2*B may be due to the fact that the SNP is linked to other functional SNPs upstream or downstream of the region investigated here, or located in other nearby KRTAPs.

The finding that CAPHI-KRTAP1-2*B of caprine KRTAP1-2 was associated with decreased cashmere fiber yield but had no effect on fiber diameter or length, possibly suggests that the presence of $B$ may lead to there being a lower number of secondary wool follicles, and hence, less cashmere fibers would be produced. This effect appears to be similar to that reported for its ovine orthologue in which variation in KRTAP1-2 was found to affect wool fiber weight traits, but not fiber diameter-associated traits and fiber length [19]. The results from this study suggest that breeding against CAPHI-KRTAP1-2*B would lead to a high cashmere fiber yield without compromising the fiber diameter, potentially providing a gene marker for improving cashmere fiber production.

Supplementary Materials: The following is available online at: https://www.mdpi.com/article/10 .3390 /genes12050625/s1, Supplementary Figure S1. Adult and juvenile Longdong cashmere goats. 
Author Contributions: Conceptualization, M.Z., J.W. and H.Z. (Huitong Zhou); methodology, M.Z., J.H., Y.L., X.L. and S.L.; investigation, M.Z., J.H. and S.L.; data analysis, M.Z., X.L., K.Z. and H.Z. (Huimin Zhen) resources, J.W. and Y.L.; writing-original draft preparation, M.Z., H.Z. (Huitong Zhou), J.W. and J.G.H.H.; writing-review and editing, M.Z., H.Z. (Huitong Zhou), J.W., K.Z., H.Z. (Huimin Zhen) and J.G.H.H.; supervision, H.Z. (Huitong Zhou), J.W. and J.G.H.H.; project administration, J.W. and Y.L.; funding acquisition, J.W. and Y.L. All authors have read and agreed to the published version of the manuscript.

Funding: This work was financially supported by the fund for Basic Research Creative Groups of Gansu Province (18JR3RA190), Fuxi Young Talents Fund of Gansu Agricultural University (Gaufx02Y02), Gansu Provincial Finance Department Project (033-041041) and the Major Scientific and Technology Project of Qingyang City.

Institutional Review Board Statement: The goats investigated were managed and handled in accordance with the guidelines for care and experimental animals established by the Ministry of Science and Technology of the People's Republic of China (Approval number 2006-398), and the collection of caprine blood and skin samples was also permitted by Gansu Agricultural University (Lanzhou, China).

Informed Consent Statement: Not applicable.

Data Availability Statement: The data presented in this study are available on request from the corresponding author.

Conflicts of Interest: The authors declare no conflict of interest.

\section{References}

1. Powell, B.C.; Rogers, G.E. The role of keratin proteins and their genes in the growth, structure and properties of hair. EXS 1997, 78, 59-148. [CrossRef]

2. Gong, H.; Zhou, H.; Forrest, R.H.; Li, S.; Wang, J.; Dyer, J.M.; Luo, Y.; Hickford, J.G.H. Wool keratin-associated protein genes in sheep-a review. Genes 2016, 7, 24. [CrossRef] [PubMed]

3. Bai, L.; Wang, J.; Zhou, H.; Gong, H.; Tao, J.; Hickford, J.G.H. Identification of ovine KRTAP28-1 and its association with wool weight and mean fibre diameter-associated traits. Animals 2019, 9, 142. [CrossRef] [PubMed]

4. Gong, H.; Zhou, H.; Wang, J.; Li, S.; Luo, Y.; Hickford, J.G.H. Characterisation of an ovine keratin associated protein (KAP) gene, which would produce a protein rich in glycine and tyrosine, but lacking in cysteine. Genes 2019, 10, 848. [CrossRef] [PubMed]

5. Parris, D.; Swart, L.S. Studies on the high-sulphur proteins of reduced mohair. The isolation and amino acid sequence of protein scmkb-m1.2. Biochem. J. 1975, 145, 459-467. [CrossRef] [PubMed]

6. Zhao, M.; Zhou, H.; Hickford, J.G.H.; Gong, H.; Wang, J.; Hu, J.; Liu, X.; Li, S.; Hao, Z.; Luo, Y. Variation in the caprine keratin-associated protein 15-1 (KAP15-1) gene affects cashmere fibre diameter. Arch. Anim. Breed. 2019, 62, 125-133. [CrossRef] [PubMed]

7. Wang, J.; Zhou, H.; Luo, Y.; Zhao, M.; Gong, H.; Hao, Z.; Hu, J.; Hickford, J.G.H. Variation in the caprine KAP24-1 gene affects cashmere fibre diameter. Animals 2019, 9, 15. [CrossRef]

8. Wang, J.; Zhou, H.; Hickford, J.G.H.; Zhao, M.; Gong, H.; Hao, Z.; Shen, J.; Hu, J.; Liu, X.; Li, S.; et al. Identification of caprine KRTAP28-1 and its effect on cashmere fiber diameter. Genes 2020, 11, 121. [CrossRef] [PubMed]

9. Zhao, M.; Zhou, H.; Luo, Y.; Wang, J.; Hu, J.; Liu, X.; Li, S.; Hao, Z.; Jin, X.; Song, Y. Variation in the caprine keratin-associated protein 27-1 gene is associated with cashmere fiber diameter. Genes 2020, 11, 934. [CrossRef] [PubMed]

10. Liu, H.; Li, N.; Jia, C.; Zhu, X.; Jia, Z. Effect of the polymorphisms of keratin associated protein 8.2 gene on fibre traits in Inner Mongolia cashmere goats. Asian Australas. J. Anim. Sci. 2007, 20, 821-826. [CrossRef]

11. Wang, J.; Che, L.; Hickford, J.G.H.; Zhou, H.; Hao, Z.; Luo, Y.; Hu, J.; Liu, X.; Li, S. Identification of the caprine keratin-associated protein 20-2 (KAP20-2) gene and its effect on cashmere traits. Genes 2017, 8, 328. [CrossRef] [PubMed]

12. Wang, J.; Hao, Z.; Zhou, H.; Luo, Y.; Hu, J.; Liu, X.; Li, S.; Hickford, J.G.H. A keratin-associated protein (KAP) gene that is associated with variation in cashmere goat fleece weight. Small Rumin. Res. 2018, 167, 104-109. [CrossRef]

13. Itenge-Mweza, T.O.; Forrest, R.H.J.; Mckenzie, G.W.; Hogan, A.; Abbott, J.; Amoafo, O.; Hickford, J.G.H. Polymorphism of the KAP1.1, KAP1.3 and K33 genes in Merino sheep. Mol. Cell. Probes 2007, 21, 338-342. [CrossRef] [PubMed]

14. Gong, H.; Zhou, H.; Hickford, J.G.H. Polymorphism of the ovine keratin-associated protein 1-4 gene (KRTAP1-4). Mol. Biol. Rep. 2010, 37, 3377-3380. [CrossRef] [PubMed]

15. Gong, H.; Zhou, H.; Yu, Z.; Dyer, J.M.; Plowman, J.E.; Hickford, J.G.H. Identification of the ovine keratin-associated protein KAP1-2 gene (KRTAP1-2). Exp. Dermatol. 2011, 20, 815-819. [CrossRef]

16. Roldan, D.L.; Dodero, A.M.; Bidinost, F.; Taddeo, H.R.; Allain, D.; Poli, M.A.; Elsen, J.M. Merino sheep: A further look at quantitative trait loci for wool production. Animal 2010, 4, 1330-1340. [CrossRef] [PubMed] 
17. Rogers, G.R.; Hickford, J.G.H.; Bickerstaffe, R. Polymorphism in two genes for B2 high sulfur proteins of wool. Anim. Genet. 1994, 25, 407-415. [CrossRef] [PubMed]

18. Zhou, H.; Visnovska, T.; Gong, H.; Schmeier, S.; Hickford, J.G.H.; Ganley, A.R.D. Contrasting patterns of coding and flanking region evolution in mammalian keratin associated protein-1 genes. Mol. Phylogenet. Evol. 2019, 133, 352-361. [CrossRef]

19. Gong, H.; Zhou, H.; Hodge, S.; Dyer, J.M.; Hickford, J.G.H. Association of wool traits with variation in the ovine KAP1-2 gene in Merino cross lambs. Small Rumin. Res. 2015, 124, 24-29. [CrossRef]

20. Zhou, H.; Hickford, J.G.H.; Fang, Q. A two-step procedure for extracting genomic DNA from dried blood spots on filter paper for polymerase chain reaction amplification. Anal. Biochem. 2006, 354, 159-161. [CrossRef]

21. Byun, S.O.; Fang, Q.; Zhou, H.; Hickford, J.G.H. An effective method for silver-staining DNA in large numbers of polyacrylamide gels. Anal. Biochem. 2009, 385, 174-175. [CrossRef] [PubMed]

22. Gong, H.; Zhou, H.; Hickford, J.G.H. Diversity of the glycine/tyrosine-rich keratin-associated protein 6 gene (KAP6) family in sheep. Mol. Biol. Rep. 2011, 38, 31-35. [CrossRef] [PubMed]

23. Gong, H.; Zhou, H.; McKenzie, G.W.; Yu, Z.; Clerens, S.; Dyer, J.M.; Plowman, J.E.; Wright, M.W.; Arora, R.; Bawden, C.S.; et al. An updated nomenclature for keratin-associated proteins (KAPs). Int. J. Biol. Sci. 2012, 8, 258-264. [CrossRef] [PubMed]

24. Gong, H.; Zhou, H.; McKenzie, G.W.; Hickford, J.G.H.; Luo, Y.; Clerens, S.; Dyer, J.M.; Plowman, J.E. Emerging issues with the current keratin-associated protein nomenclature. Int. J. Trichol. 2010, 2, 104-115. [CrossRef]

25. Gong, H.; Zhou, H.; Plowman, J.E.; Dyer, J.M.; Hickford, J.G.H. Analysis of variation in the ovine ultra-high sulphur keratinassociated protein KAP5-4 gene using PCR-SSCP technique. Electrophoresis 2010, 31, 3545-3547. [CrossRef]

26. Zhou, H.; Gong, H.; Wang, J.; Dyer, J.M.; Luo, Y.; Hickford, J.G.H. Identification of four new gene members of the KAP6 gene family in sheep. Sci. Rep. 2016, 6, 24074. [CrossRef] [PubMed]

27. Yu, H.; Wang, X.; Chen, H.; Wang, M.; Zhao, M.; Lan, X.; Lei, C.; Wang, K.; Lai, X.; Wang, X. The polymorphism of a novel 30bp-deletion mutation at KAP9.2 locus in the cashmere goat. Small Rumin. Res. 2008, 80, 111-115. [CrossRef]

28. Wang, J.; Zhou, H.; Zhu, J.; Hu, J.; Liu, X.; Li, S.; Luo, Y.; Hickford, J.G.H. Identification of the ovine keratin-associated protein 15-1 gene (KRTAP15-1) and genetic variation in its coding sequence. Small Rumin. Res. 2017, 153, 131-136. [CrossRef]

29. Smith, G.R. Homologous recombination near and far from DNA breaks: Alternative roles and contrasting views. Annu. Rev. Genet. 2001, 35, 243-274. [CrossRef] [PubMed]

30. Nackley, A.G.; Shabalina, S.A.; Tchivileva, I.E.; Satterfield, K.; Korchynskyi, O.; Makarov, S.S.; Maixner, W.; Diatchenko, L. Human catechol-O-methyltransferase haplotypes modulate protein expression by altering mRNA secondary structure. Science 2006, 314, 1930-1933. [CrossRef]

31. Duan, J.; Wainwright, M.S.; Comeron, J.M.; Saitou, N.; Sanders, A.R.; Gelernter, J.; Gejman, P.V. Synonymous mutations in the human dopamine receptor D2 (DRD2) affect mRNA stability and synthesis of the receptor. Hum. Mol. Genet. 2003, 12, 205-216. [CrossRef] [PubMed]

32. Gotea, V.; Gartner, J.J.; Qutob, N.; Elnitski, L.; Samuels, Y. The functional relevance of somatic synonymous mutations in melanoma and other cancers. Pigment Cell Melanoma Res. 2015, 28, 673-684. [CrossRef] 